\title{
Safety and effectiveness of switching from infliximab to etanercept in patients with rheumatoid arthritis: results from a large Japanese postmarketing surveillance study
}

\author{
Takao Koike - Masayoshi Harigai - Shigeko Inokuma - Naoki Ishiguro • \\ Junnosuke Ryu - Tsutomu Takeuchi - Yoshiya Tanaka • Hisashi Yamanaka • \\ Koichi Fujii · Takunari Yoshinaga $\cdot$ Bruce Freundlich $\cdot$ Michio Suzukawa
}

Received: 7 October 2010/ Accepted: 22 January 2011/Published online: 18 February 2011

(C) The Author(s) 2011. This article is published with open access at Springerlink.com

\begin{abstract}
Finding an effective treatment strategy for rheumatoid arthritis (RA) patients who have not benefited from previous tumor necrosis factor- $\alpha$ antagonist treatment is important for minimizing RA disease activity and improving patient outcomes. The aim of this study was to compare the safety and effectiveness of etanercept in patients with and without infliximab (IFX) treatment experience. Patients $(n=7,099)$ from a large postmarketing observational study of etanercept use in Japan were divided into 2 cohorts based on previous IFX use (pre-IFX and non-IFX). Baseline characteristics were assessed in each cohort. Adverse events (AEs) and European League Against Rheumatism (EULAR) responses were monitored every 4 weeks for 24 weeks. At baseline, pre-IFX patients were younger and had fewer comorbidities and a shorter RA duration than non-IFX patients. During the study, pre-IFX patients received concomitant methotrexate more often than non-IFX
\end{abstract}

\section{T. Koike}

Hokkaido University Graduate School of Medicine,

Hokkaido, Japan

\section{Harigai}

Tokyo Medical Dental University Graduate School,

Tokyo, Japan

S. Inokuma

Japanese Red Cross Medical Center, Tokyo, Japan

N. Ishiguro

Nagoya University Graduate School of Medicine,

Nagoya, Japan

J. Ryu

Nihon University School of Medicine, Tokyo, Japan

T. Takeuchi

Keio University, Tokyo, Japan patients. The incidence of AEs and serious AEs were significantly lower in pre-IFX patients, as was the percentage of patients who discontinued treatment. Both cohorts had significant improvement $(P<0.001)$ in EULAR responses at the end of the treatment period. This study demonstrated that etanercept was effective and well tolerated in active RA patients with and without prior IFX treatment.

Keywords Etanercept · Infliximab - Postmarketing surveillance study $\cdot$ Rheumatoid arthritis $\cdot$ TNF- $\alpha$ antagonists

\section{Introduction}

The goals of managing rheumatoid arthritis (RA) are to control or prevent damage to the joints, decrease pain, and

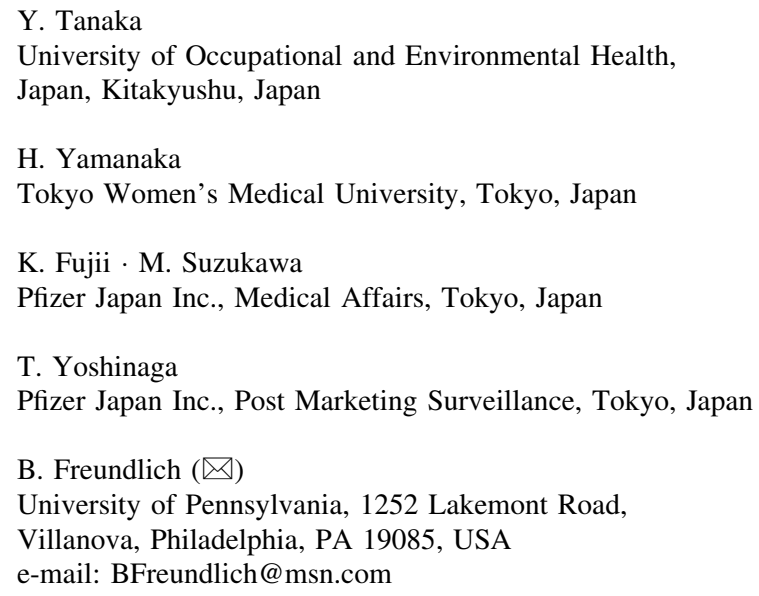


prevent loss of function [1]. Remission as defined by the European League against Rheumatism (EULAR; disease activity score in 28 joints [DAS28] $<2.6$ ) is currently a realistic and achievable goal of RA treatment $[2,3]$. There are various treatment strategies to achieve remission, such as combination therapy with disease-modifying antirheumatic drugs (DMARDs) or therapy with tumor necrosis factor $-\alpha(\mathrm{TNF}-\alpha)$ inhibitors (monotherapy or combination therapy) $[3,4]$. Combination therapy using TNF- $\alpha$ antagonists plus traditional DMARDs is a common strategy for the treatment of RA and improves the clinical outcomes in patients who previously received monotherapy [5]. In particular, the combination of TNF- $\alpha$ antagonists and methotrexate (MTX) results in better clinical and radiographic responses than when either agent is used alone $[6$, 7].

A relatively recent concern in RA disease management is the treatment of patients who do not respond to initial anti-TNF- $\alpha$ therapy. Up to approximately one-third of patients treated with TNF- $\alpha$ antagonists fail to respond or develop adverse events (AEs) that lead to treatment discontinuation [8-10]. The use of biologics such as rituximab [11] and abatacept [12] with a different mechanism of action may be an option for such patients; however, several studies have shown that patients who do not tolerate or respond to initial treatment with a TNF- $\alpha$ antagonist can benefit by switching to a different TNF- $\alpha$ antagonist (despite the fact that both agents target TNF- $\alpha$ ) [13-21]. Conclusions regarding the benefit of switching TNF- $\alpha$ inhibitors from these studies have, however, been limited by relatively small patient numbers.

The Japanese postmarketing survey for etanercept (ETN; a fully human soluble TNF receptor fusion protein) registered all patients treated with ETN in Japan, including a large number of patients who had switched from infliximab (IFX) to ETN therapy. The purpose of this post hoc analysis of interim data (for the first 7,099 patients; analysis for all 13,894 patients is still ongoing) from the postmarketing survey is to evaluate the safety and effectiveness of ETN among patients who discontinued IFX treatment because of a lack of effectiveness or AEs.

\section{Patients and methods}

\section{Patients}

This study enrolled 13,894 Japanese patients with RA (aged $\geq 18$ years) with and without prior IFX experience participating in a postmarketing surveillance study of ETN use between March 2005 and April 2007. This Post-Marketing Surveillance Program was conducted under Pharmaceutical Affairs Law, which collects data and information from usage of products within product labeling under daily clinical practice. Patient eligibility for ETN treatment was evaluated according to the Japan College of Rheumatology guidelines [22], and the protocol was reviewed and approved by the Japanese Ministry of Health, Labor, and Welfare. ETN was indicated for patients with active RA despite DMARD treatment for $>3$ months, $\geq 6$ tender joints, $\geq 6$ swollen joints, and erythrocyte sedimentation rate $(E S R) \geq 28 \mathrm{~mm} / \mathrm{h}$ or $\mathrm{C}$-reactive protein $(\mathrm{CRP}) \geq 2.0 \mathrm{mg} / \mathrm{dL}$. Patients also had to have a low risk for opportunistic infections (white blood cell count $\geq 4,000$ / $\mathrm{mm}^{3}$, peripheral blood lymphocyte count $\geq 1,000 / \mathrm{mm}^{3}$, and negative serum $\beta$-D-glucan). Contraindications for ETN treatment included ongoing infection, history of serious infection in the previous 6 months, history of tuberculosis infection or Pneumocystis carinii pneumonia, congestive heart failure, or malignancy or demyelinating disease. Mandatory chest radiographs and tuberculin tests were conducted before initiation of treatment.

\section{Study design/assessments}

Patients receiving ETN were divided into 2 groups based on their history of IFX use and were categorized as either having previous IFX treatment (pre-IFX) or no prior IFX treatment (non-IFX). Etanercept $10-25 \mathrm{mg}$ was administered subcutaneously twice weekly. Patients could selfinject after receiving appropriate training from healthcare professionals. Safety and effectiveness data were collected every 4 weeks for 24 weeks. The primary effectiveness endpoint was EULAR response.

\section{Statistical analysis}

In this post hoc analysis, missing effectiveness data were accounted for using last-observation-carried-forward (LOCF) methods, except for baseline values, which were not carried forward. Fisher's exact test and $t$-test were used to assess differences between pre-IFX patients and nonIFX patients in baseline characteristics, treatment effectiveness (DAS28 response according to EULAR criteria), and serious AEs. Continuation rates of etanercept between the pre-IFX and non-IFX groups were compiled to generate a Kaplan-Meier plot and were tested using log-rank test. Furthermore, Cox proportional hazard models were applied to estimate relative risks and $95 \%$ CIs of serious AEs in relation to pre-IFX treatment, after adjustment for major confounders including age, sex, Steinbrocker functional class 4 , duration of RA, history of infectious disease, history of tuberculosis, presence of any comorbidities, and concomitant DMARD use. Also, multiple logistic regression models were used to estimate the effect of pre-IFX treatment on the likelihood of achieving a moderate to 
good EULAR response after adjustment for major confounders. All statistical analyses were performed using SAS, version 8.2, software (SAS Institute, Inc., Cary, NC). Two-sided $P$ values of less than 0.05 were considered to indicate statistical significance.

\section{Results}

Patient characteristics

This interim analysis evaluated the safety and effectiveness of ETN among the first 7,099 patients (908 pre-IFX and 6,191 non-IFX patients) out of 13,894 patients enrolled. Most baseline characteristics differed significantly between pre-IFX and non-IFX patients (Table 1). Patients in the pre-IFX group tended to be younger than patients in the non-IFX group (mean age, 54.2 and 58.9 years, respectively, $P<0.001)$ and had a shorter duration of RA $(9.0$ and 9.9 years, respectively, $P<0.001)$ and fewer comorbidities (52.0 and 59.1\%, respectively, $P<0.001$ ). In the pre-IFX patients, concomitant DMARD use at the enrollment to the study was higher compared with non-IFX patients (87.1 and $68.7 \%$, respectively, $P<0.001$ ), as was the concomitant use of MTX (80.9 and $48.6 \%$, respectively, $P<0.001)$.

Treatment rationale and compliance

Within the cohort of pre-IFX patients $(n=908)$, most patients $(94 \%, n=856)$ switched from IFX to ETN treatment because of a lack of IFX effectiveness. In cases in which initial IFX treatment was effective $(6 \%, n=52)$, the majority of patients $(73 \%, n=38)$ switched to ETN because of treatment-related AEs.

Etanercept compliance was monitored in pre- and nonIFX cohorts for 24 weeks. Pre-IFX group showed

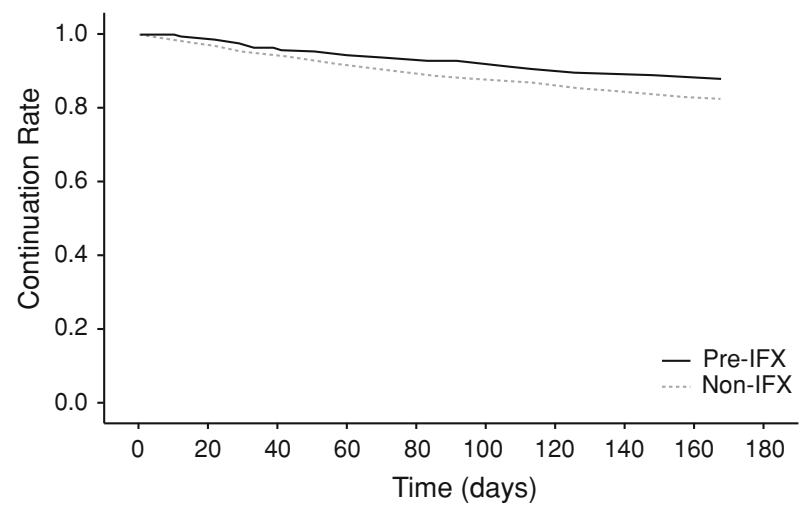

Fig. 1 Kaplan-Meier analysis for continuation rates of etanercept between the pre-IFX and non-IFX groups. IFX = infliximab. $P<0.001$ for pre-IFX vs. non-IFX (log-rank test)

significantly higher continuation rate than non-IFX group ( $87.9 \%$ vs. $82.3 \%, P<0.001)$ (Fig. 1). Of the entire study population, $17.0 \%(n=1,208)$ of patients treated with ETN discontinued use, and most discontinued because of AEs $(8.6 \%, n=608)$ rather than a loss of effectiveness $(2.6 \% n=185)$. Among the patients who discontinued treatment because of AEs, pre-IFX patients had a significantly lower rate of ETN discontinuation compared with non-IFX patients $(5.0 \%$ vs. $9.1 \% ; P<0.001)$. There was no statistical difference in discontinuations due to lack of effectiveness between pre- and non-IFX patients.

\section{Safety}

Approximately $34 \%(n=2,424)$ of the patients in this study reported an AE during the observation period. For both groups, the most common $\mathrm{AE}$ was infection. Overall, $6.4 \%(n=452)$ of patients reported a serious AE during the study. The incidence of AEs and serious AEs (SAEs) was significantly lower in the pre-IFX group than in the non-IFX group $(P<0.001$ and $P=0.004$, respectively;
Table 1 Patient characteristics

DAS28 Disease Activity Score including 28-joint count; $D M A R D s$ disease-modifying antirheumatic drugs; IFX infliximab; MTX methotrexate; $n s$ not significant; $R A$ rheumatoid arthritis

$* n=501$ for patients switching from IFX; $n=4,142$ for patients not switching from IFX

\begin{tabular}{llll}
\hline & Pre-IFX patients & Non-IFX patients & $P$ value \\
\hline $\begin{array}{l}\text { Number of patients } \\
\text { Sex, } n(\%)\end{array}$ & 908 & 6,191 & \\
$\quad$ Men & $186(20.5)$ & $1,160(18.7)$ & $\mathrm{ns}$ \\
$\quad$ Women & $722(79.5)$ & $5,031(81.3)$ & $\mathrm{ns}$ \\
Mean age $\pm \mathrm{SD}$, years & $54.2 \pm 13.2$ & $58.9 \pm 12.7$ & $<0.001$ \\
Mean body weight $\pm \mathrm{SD}, \mathrm{kg}$ & $54.2 \pm 9.8$ & $53.1 \pm 10.2$ & 0.018 \\
Presence of any past history, $n(\%)$ & $224(24.7)$ & $1,855(30.0)$ & $<0.001$ \\
Comorbidities present, $n(\%)$ & $472(52.0)$ & $3,661(59.1)$ & $<0.001$ \\
Mean duration of RA, years & 9.0 & 9.9 & $<0.001$ \\
Previous steroid use, $n(\%)$ & $824(90.8)$ & $5,248(84.8)$ & $<0.001$ \\
Mean DAS28 \pm SD & $6.1 \pm 1.2$ & $6.0 \pm 1.2$ & $\mathrm{~ns}$ \\
Concomitant use of DMARDs, $\%$ & 87.1 & 68.7 & $<0.001$ \\
Concomitant use of MTX, $n(\%)$ & 80.9 & 48.6 & $<0.001$ \\
\hline
\end{tabular}


Table 2). In patients who received MTX concomitant with ETN, there was no increase in the risk of SAEs relative to ETN monotherapy (Fig. 2). The incidence of SAEs in nonIFX patients treated with doses of MTX $\geq 10 \mathrm{mg} / \mathrm{wk}$ was significantly lower than in patients treated with ETN alone $(P=0.019)$. Compared with the non-IFX group, pre-IFX patients had a non-significantly lower risk for SAE occurrence (multivariate hazard ratio, 0.75; 95\% CI, 0.54-1.06; $P=0.098)$.

\section{Effectiveness}

Etanercept was effective, as measured by EULAR response through the treatment period, in both pre-IFX and non-IFX patients. The majority of pre-IFX patients (>80\%) responded to ETN treatment (Fig. 3). According to the EULAR response criteria of no response, moderate response, and good response, the number of good responses increased significantly $(P<0.05)$ at week 8 and beyond in the non-IFX group and at week 12 and beyond in the preIFX group $(P<0.05)$. Remission was achieved in $14.4 \%$ of the patients in the pre-IFX group after switching to ETN (vs. $16.6 \%$ of the patients in the non-IFX group). There was no significant difference in achieving a good or moderate EULAR response between the non-IFX and pre-IFX groups (multivariate odds ratio, $0.93 ; 95 \% \mathrm{CI}, 0.70-1.25$; $P=0.64)$.

\section{Discussion}

In clinical practice, it is important to consider the benefit of prescribing a second TNF- $\alpha$ antagonist if an initial anti$\mathrm{TNF}-\alpha$ treatment has not been effective. Indeed, multiple $\mathrm{TNF}-\alpha$ inhibitors are currently in clinical use, and although all TNF- $\alpha$ inhibitors have the same target [23], each drug is unique in its mechanism of action and pharmacologic properties (Table 3) [24-26], which can result in variations in clinical outcomes. In this study of 7,099 Japanese patients with RA, the largest study to date to evaluate the benefit of TNF- $\alpha$ switching, ETN was effective in patients with a history of prior IFX use as well as in those who were naive to IFX therapy. In the case of patients for whom prior IFX therapy had failed and who were subsequently treated with ETN, $>80 \%$ were able to attain a moderate to good EULAR response by the end of the study period, similar to
Table 2 Incidence of adverse events

IFX infliximab; $n s$ not significant

Fig. 2 Incidence rate of serious adverse events by dose of MTX. IFX infliximab; $M T X$ methotrexate. $* P<0.05$ for all doses versus $0 \mathrm{mg}$ MTX (Fisher's exact test). Values in parentheses indicate number of subjects per group

\begin{tabular}{lcccl}
\hline Adverse event, $n(\%)$ & $\begin{array}{l}\text { Pre-IFX patients } \\
(n=908)\end{array}$ & $\begin{array}{l}\text { Non-IFX patients } \\
(n=6,191)\end{array}$ & $\begin{array}{l}\text { Total } \\
(n=7,099)\end{array}$ & $P$ value \\
\hline Any adverse event & $265(29.2)$ & $2,159(34.9)$ & $2,424(34.1)$ & $<0.001$ \\
Serious adverse events & $42(4.6)$ & $500(8.1)$ & $542(7.6)$ & $<0.001$ \\
Death & $2(0.2)$ & $31(0.5)$ & $33(0.5)$ & $\mathrm{ns}$ \\
Malignancy & $1(0.1)$ & $17(0.3)$ & $18(0.3)$ & $\mathrm{ns}$ \\
Serious infection & $23(2.5)$ & $202(3.3)$ & $225(3.2)$ & $\mathrm{ns}$ \\
Non-serious infection & $55(6.1))$ & $473(7.6)$ & $528(7.4)$ & $\mathrm{ns}$ \\
\hline
\end{tabular}

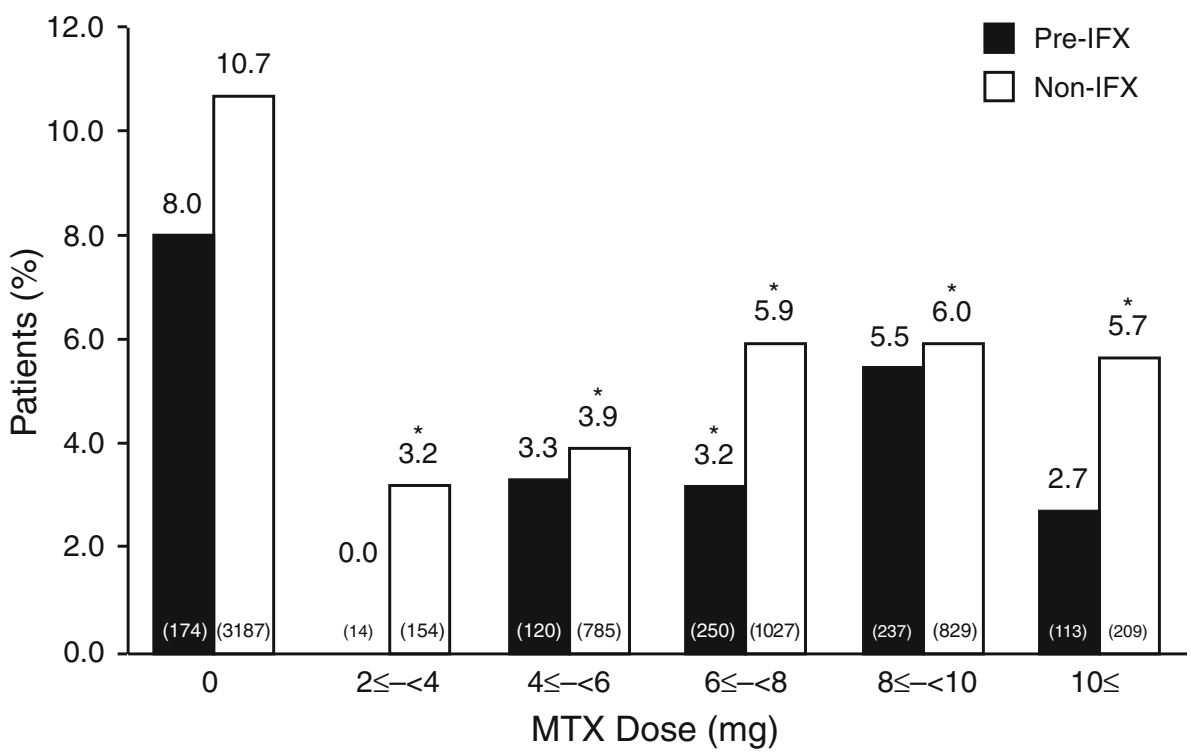


Fig. 3 European League Against Rheumatism responses. IFX infliximab. $* P<0.05$ versus week 4 for good responders (Fisher's exact test)

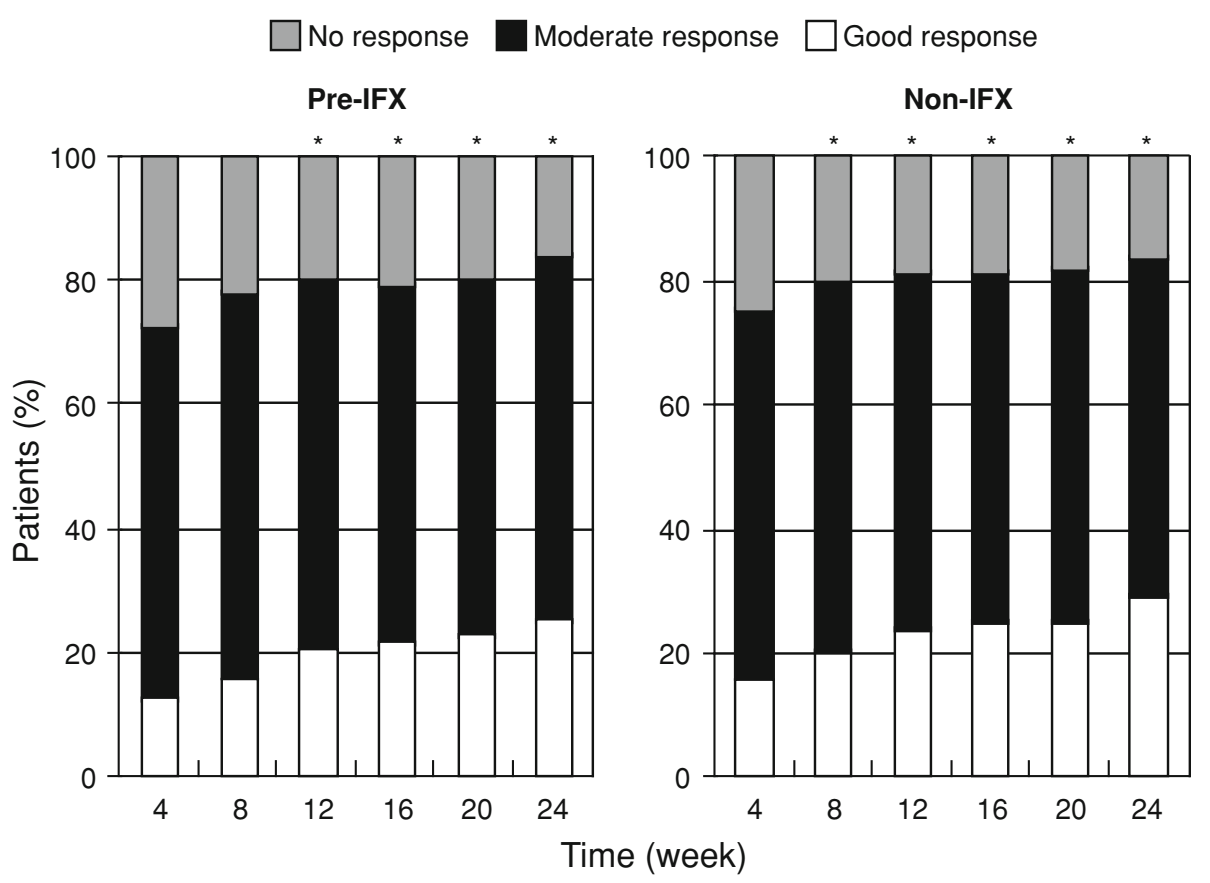

Table 3 Differences between ETN and IFX

\begin{tabular}{lll}
\hline Difference in mode of action & ETN & IFX \\
\hline MTX effects on pharmacokinetics [25] & None & Increase in serum concentration \\
Specificity [26] & TNF alpha/LT alpha & TNF alpha \\
Transmembrane TNF binding/neutralization [26] & ++ & +++ \\
Half-life, days [25] & 4.8 & 9.5 \\
In vitro complement activation [25] & No & Yes \\
Structure [26] & Hu & Mo/Hu chimeric \\
& sTNFR2-Fc $\gamma$ l & IgG $\kappa$ \\
Neutralizing antibody [24] & No & Yes \\
Reverse signaling [26] & & +++ \\
Apoptosis [26] & \pm & +++ \\
Cytokine suppression [26] & \pm & High
\end{tabular}

\pm very weak; ++ moderate; +++ strong

ETN etanercept; Fc fusion; Hu human; IFX infliximab; IgG immunoglobulin G; LT lymphotoxin; Mo murine; MTX methotrexate; TNF tumor necrosis factor; $s T N F R 2$ soluble TNF receptor 2

the effectiveness observed in IFX-naive patients treated with ETN. Moreover, ETN was able to induce remission in a subset of patients for whom prior IFX therapy had failed. Importantly, the majority (810 of $860 ; 94 \%$ ) of pre-IFX patients in this study had discontinued initial IFX treatment because of a lack of effectiveness; therefore, our data are consistent with smaller scale studies that showed that patients who discontinue IFX can respond effectively to subsequent ETN treatment [15-21, 27]. In contrast to a study demonstrating that patients switching from ETN to IFX required higher doses of IFX when compared with ETN-naive patients [13], IFX-treated patients in the present study did not require higher doses of ETN to achieve responses compared to IFX-naive patients.

Overall, treatment continuation was good in both groups, regardless of previous IFX experience, and was at least as good as continuation rates observed in other IFXto-ETN switching studies [20, 27, 28]. Regardless of prior treatment history, most patients continued to receive ETN for the duration of the study. Pre-IFX patients had a slightly higher rate of continuation throughout the study and significantly higher participation at the end of the treatment period compared with non-IFX patients. Significantly, fewer pre-IFX patients experienced AEs that led to 
discontinuation compared with IFX-naive patients. Generally, pre-IFX patients were younger and healthier (fewer comorbidities) compared with IFX-naive patients, which may contribute to the lower rate of ETN discontinuation observed in the pre-IFX group.

The most common AE reported among all patients during the study was non-serious infection. There were no significant differences in the types of AEs reported by pre- and non-IFX patients, suggesting that the safety profile of ETN is not changed by previous IFX experience. Overall, the incidence of AEs and SAEs was lower among patients with previous IFX exposure, which is encouraging given that a proportion of these patients discontinued previous IFX treatment because of AEs related to IFX.

Many RA treatment regimens that use biologic DMARDs also incorporate MTX, and the tolerability of multidrug treatment regimens is a common concern. Although MTX is not consistently used in ETN regimens, MTX is usually administered with IFX because MTX inhibits the production of human antichimeric antibodies, which can interfere with treatment effectiveness and induce autoimmune sequelae [29, 30]. MTX is currently approved as a second-line agent in Japan, and the recommended dose is lower (upper limit is $8 \mathrm{mg} / \mathrm{wk}$ ) than that in the European Union or the United States, owing to the higher incidence of AEs observed among Japanese patients in MTX clinical trials [31]. In this study, the concomitant use of MTX and ETN did not cause an increase in SAEs in pre- or non-IFX patients compared with patients receiving ETN monotherapy, suggesting that MTX use is not a major factor in predicting SAEs in these patients. It should be noted that more pre-IFX patients received concomitant MTX therapy compared with non-IFX patients. Although the reasons for increased tolerability to the combination of ETN and MTX are not clear, pre-IFX patients tended to be younger, had a shorter duration of RA, and had fewer comorbidities when compared with non-IFX patients. These data imply that patients healthy enough to be treated with MTX may have a lower incidence of SAEs resulting from combination therapy.

The present study is limited, in part, by its observational nature. Patients were followed for only up to 6 months, and radiographic analysis was not performed to confirm effectiveness. In addition, the period of IFX treatment and the period between the final infusion of IFX and the first injection of ETN were confirmed only for a subset of patients. This study does not definitively demonstrate whether ETN treatment is effective for all patients with RA who are non-responsive to IFX, nor does it address the issue of recurrence of AEs in patients who switched from IFX treatment because of AEs. In addition, differences in baseline patient demographics with regard to age, disease onset and duration, background DMARD therapy, and comorbidities may have affected the results.

The interim analysis of this large observational registry study demonstrated, in a real-world setting, the safety and effectiveness of ETN treatment in patients with active RA who were switched from previous IFX treatment as a result of lack of effectiveness or AEs. ETN treatment was effective and well tolerated in both pre-IFX and non-IFX patients. Overall, patients with prior IFX experience had safety and effectiveness outcomes that were as good as those of patients who were naive to IFX treatment.

Acknowledgments The authors wish to acknowledge the contributions of the late Professor Kazuhiko Inoue, MD, PhD, who participated in this work. The authors also wish to thank all participating physicians and registered patients. The Etanercept Post-Marketing Surveillance Committee of the Japan College of Rheumatology was created in response to a request for assistance from the Ministry of Health, Labor, and Welfare (MHLW) of Japan. The role of the committee is to provide independent advice to Wyeth K. K. (Wyeth was integrated into Pfizer in October 2009) on the conduct of the Post-Marketing Surveillance Program mandated by the MHLW and on the results thereof. Participation on this committee is not compensated. The authors wish to thank John E. Fincke, PhD, and Susan DeRocco, PhD, whose work was funded by Wyeth Research, for providing assistance in the drafting of this manuscript. This study was sponsored by Wyeth, and clinical fees were shared by Wyeth K. K. (Wyeth was integrated into Pfizer in October 2009) and Takeda Pharmaceutical Company Limited, Wyeth K. K.'s copromotion partner for etanercept in Japan.

Role of the Sponsor Pursuant to the Pharmaceutical Affairs Law of Japan and the regulations promulgated there under, the Sponsor (Wyeth was integrated into Pfizer in October 2009) was required to conduct a PMS program as a condition for the marketing approval of etanercept. Wyeth was responsible for the development of the study protocol (with instruction from PMDA and advice from JCR PMS committee) and for the initial analysis of the data.

Conflict of interest Doctors T. Koike, M. Harigai, S. Inokuma, N. Ishiguro, J. Ryu, T. Takeuchi, Y. Tanaka, and H. Yamanaka are all members of the Etanercept Postmarketing Surveillance Committee of the Japan College of Rheumatology. It is the belief of the first author that this position does not constitute a Conflict of Interest. The doctors participated in the review and analysis of the PMS data in their capacity as Committee members and are so listed. The financial relationships of the authors with all manufacturers of biological products used in the management of RA are as follows: \#1 is a research grant to the institute to which they are affiliated; \#2 is a consulting fee; \#3 is membership of a speakers' bureau; \#4 is a fulltime employee, and \#5 is a previous employee of Pfizer.

T. Koike, Abbott Japan, 1; Bristol-Myers Squibb, 1; Chugai Pharmaceutical Co. Ltd, 1; Eisai Co. Ltd, 1; Mitsubishi Tanabe Pharma, 1; Takeda Pharmaceutical Co. Ltd, 1; Wyeth KK, 1; Otsuka Pharmaceutical Co. Ltd, 2; Abbott Japan, 3; Bristol-Myers Squibb, 3; Chugai Pharmaceutical Co. Ltd, 3; Eisai Co. Ltd, 3; Mitsubishi Tanabe Pharma, 3; Takeda Pharmaceutical Co. Ltd, 3; Wyeth KK, 3; M. Harigai, Abbott Japan, 1; Bristol-Myers Squibb, 1; Chugai Pharmaceutical Co. Ltd, 1; Eisai Co. Ltd, 1; Mitsubishi Tanabe Pharma, 1; Pfizer Japan Inc., 1; Takeda Pharmaceutical Co. Ltd, 1; Abbott Japan, 2; Chugai Pharmaceutical Co. Ltd, 2; Mitsubishi Tanabe Pharma, 2; Abbott Japan, 3; Bristol-Myers Squibb, 3; Chugai Pharmaceutical Co. Ltd, 3; Eisai Co. Ltd, 3; Mitsubishi Tanabe 
Pharma, 3; Pfizer Japan Inc., 3; Takeda Pharmaceutical Co. Ltd, 3; S. Inokuma, None; N. Ishiguro, Abbott, 1; Chugai Pharmaceutical Co. Ltd, 1; Daiichi-Sankyo Pharmaceutical Co. Ltd, 1; Eisai Co. Ltd, 1; Mitsubishi Tanabe Pharma, 1; Takeda Pharmaceutical Co. Ltd, 1; Wyeth KK, 1; Abbott, 3; Bristol-Myers Squibb, 3; Chugai Pharmaceutical Co. Ltd, 3; Daiichi-Sankyo Pharmaceutical Co. Ltd, 3; Eisai Co. Ltd, 3; Mitsubishi Tanabe Pharma, 3; Takeda Pharmaceutical Co. Ltd, 3; Wyeth KK, 3; J. Ryu, None; T. Takeuchi, Bristol-Myers Squibb, 2; Mitsubishi Tanabe Pharma, 2; Novartis, 2; Abbott, 3; Chugai Pharmaceutical Co. Ltd, 3; Eisai Pharma, 3; Mitsubishi Tanabe Pharma, 3; Takeda Pharmaceutical Co. Ltd, 3; Y. Tanaka, Abbott, 1; Astellas Pharma Inc., 1; Chugai Pharmaceutical Co. Ltd, 1; Eisai Co. Ltd, 1; Mitsubishi Tanabe Pharma, 1; MSD KK, 1; Pfizer Inc., 1; Takeda Pharmaceutical Co. Ltd, 1; Mitsubishi Tanabe Pharma, 2; Abbott, 3; Astellas Pharma Inc., 3; Chugai Pharmaceutical Co. Ltd, 3; Eisai Co. Ltd, 3; Mitsubishi Tanabe Pharma, 3; Takeda Pharmaceutical Co. Ltd, 3; H. Yamanaka, Abbott Japan, 1; Chugai Pharmaceutical Co. Ltd, 1; Eisai Co. Ltd, 1; Mitsubishi Tanabe Pharma, 1; Takeda Pharmaceutical Co. Ltd, 1; Wyeth KK, 1; Abbott Japan, 3; Chugai Pharmaceutical Co. Ltd, 3; Eisai Co. Ltd, 3; Mitsubishi Tanabe Pharma, 3; Pfizer Japan Inc., 3; Takeda Pharmaceutical Co. Ltd, 3; Wyeth KK, 3; B. Freundlich, Pfizer Inc., 5; K. Fujii, Pfizer Japan Inc., 4; T. Yoshinaga, Pfizer Japan Inc., 4; M. Suzukawa, Pfizer Japan Inc., 4.

Open Access This article is distributed under the terms of the Creative Commons Attribution Noncommercial License which permits any noncommercial use, distribution, and reproduction in any medium, provided the original author(s) and source are credited.

\section{References}

1. Guidelines for the management of rheumatoid arthritis: 2002 update (2002). Arthritis Rheum 46(2):328-346

2. Smolen JS, Aletaha D (2006) What should be our treatment goal in rheumatoid arthritis today? Clin Exp Rheumatol 24(6 Suppl 43):S7-S13

3. Emery P, Breedveld FC, Hall S, Durez P, Chang DJ, Robertson D, Singh A, Pedersen RD, Koenig AS, Freundlich B (2008) Comparison of methotrexate monotherapy with a combination of methotrexate and etanercept in active, early, moderate to severe rheumatoid arthritis (comet): A randomised, double-blind, parallel treatment trial. Lancet

4. Makinen H, Hannonen P, Sokka T (2006) Definitions of remission for rheumatoid arthritis and review of selected clinical cohorts and randomised clinical trials for the rate of remission. Clin Exp Rheumatol 24(6 Suppl 43):S22-S28

5. Donahue KE, Gartlehner G, Jonas DE, Lux LJ, Thieda P, Jonas BL, Hansen RA, Morgan LC, Lohr KN (2008) Systematic review: comparative effectiveness and harms of disease-modifying medications for rheumatoid arthritis. Ann Intern Med 148(2):124-134

6. Breedveld FC, Weisman MH, Kavanaugh AF, Cohen SB, Pavelka K, van Vollenhoven R, Sharp J, Perez JL, Spencer-Green GT (2006) The premier study: a multicenter, randomized, doubleblind clinical trial of combination therapy with adalimumab plus methotrexate versus methotrexate alone or adalimumab alone in patients with early, aggressive rheumatoid arthritis who had not had previous methotrexate treatment. Arthritis Rheum 54(1):26-37

7. Klareskog L, van der Heijde D, de Jager JP, Gough A, Kalden J, Malaise M, Martin Mola E, Pavelka K, Sany J, Settas L, Wajdula J, Pedersen R, Fatenejad S, Sanda M (2004) Therapeutic effect of the combination of etanercept and methotrexate compared with each treatment alone in patients with rheumatoid arthritis: Double-blind randomised controlled trial. Lancet 363(9410):675-681

8. Lipsky PE, van der Heijde DM, St Clair EW, Furst DE, Breedveld FC, Kalden JR, Smolen JS, Weisman M, Emery P, Feldmann M, Harriman GR, Maini RN (2000) Infliximab and methotrexate in the treatment of rheumatoid arthritis. Anti-tumor necrosis factor trial in rheumatoid arthritis with concomitant therapy study group. N Engl J Med 343(22):1594-1602

9. Moreland LW, Baumgartner SW, Schiff MH, Tindall EA, Fleischmann RM, Weaver AL, Ettlinger RE, Cohen S, Koopman WJ, Mohler K, Widmer MB, Blosch CM (1997) Treatment of rheumatoid arthritis with a recombinant human tumor necrosis factor receptor (p75)-fc fusion protein. $\mathrm{N}$ Engl $\mathrm{J}$ Med 337(3):141-147

10. Maini R, St Clair EW, Breedveld F, Furst D, Kalden J, Weisman M, Smolen J, Emery P, Harriman G, Feldmann M, Lipsky P (1999) Infliximab (chimeric anti-tumour necrosis factor alpha monoclonal antibody) versus placebo in rheumatoid arthritis patients receiving concomitant methotrexate: A randomised phase iii trial. Attract study group. Lancet 354(9194):1932-1939

11. Cohen SB, Emery P, Greenwald MW, Dougados M, Furie RA, Genovese MC, Keystone EC, Loveless JE, Burmester GR, Cravets MW, Hessey EW, Shaw T, Totoritis MC (2006) Rituximab for rheumatoid arthritis refractory to anti-tumor necrosis factor therapy: results of a multicenter, randomized, double-blind, placebo-controlled, phase iii trial evaluating primary efficacy and safety at twenty-four weeks. Arthritis Rheum 54(9):2793-2806

12. Genovese MC, Becker JC, Schiff M, Luggen M, Sherrer Y, Kremer J, Birbara C, Box J, Natarajan K, Nuamah I, Li T, Aranda R, Hagerty DT, Dougados M (2005) Abatacept for rheumatoid arthritis refractory to tumor necrosis factor alpha inhibition. N Engl J Med 353(11):1114-1123

13. Hansen KE, Hildebrand JP, Genovese MC, Cush JJ, Patel S, Cooley DA, Cohen SB, Gangnon RE, Schiff MH (2004) The efficacy of switching from etanercept to infliximab in patients with rheumatoid arthritis. J Rheumatol 31(6):1098-1102

14. Wick MC, Ernestam S, Lindblad S, Bratt J, Klareskog L, van Vollenhoven RF (2005) Adalimumab (humira) restores clinical response in patients with secondary loss of efficacy from infliximab (remicade) or etanercept (enbrel): Results from the sture registry at karolinska university hospital. Scand J Rheumatol 34(5):353-358

15. Laas K, Peltomaa R, Kautiainen H, Leirisalo-Repo M (2008) Clinical impact of switching from infliximab to etanercept in patients with rheumatoid arthritis. Clin Rheumatol 27(7):927-932

16. Iannone F, Trotta F, Montecucco C, Giacomelli R, Galeazzi M, Matucci-Cerinic M, Ferri C, Cutolo M, Maria Bambara L, Triolo G, Ferraccioli G, Valentini G, Lapadula G (2007) Etanercept maintains the clinical benefit achieved by infliximab in patients with rheumatoid arthritis who discontinued infliximab because of side effects. Ann Rheum Dis 66(2):249-252

17. Ang HT, Helfgott S (2003) Do the clinical responses and complications following etanercept or infliximab therapy predict similar outcomes with the other tumor necrosis factor-alpha antagonists in patients with rheumatoid arthritis? J Rheumatol 30(11):2315-2318

18. Brocq O, Plubel Y, Breuil V, Grisot C, Flory P, Mousnier A, Euller-Zieg L (2002) Etanercept-infliximab switch in rheumatoid arthritis. Presse Med 31(39 Pt 1):1836-1839

19. Gomez-Puerta JA, Sanmarti R, Rodriguez-Cros JR, Canete JD (2004) Etanercept is effective in patients with rheumatoid arthritis with no response to infliximab therapy. Ann Rheum Dis 63(7):896

20. Haraoui B, Keystone EC, Thorne JC, Pope JE, Chen I, Asare CG, Leff JA (2004) Clinical outcomes of patients with rheumatoid 
arthritis after switching from infliximab to etanercept. J Rheumatol 31(12):2356-2359

21. van Vollenhoven R, Harju A, Brannemark S, Klareskog L (2003) Treatment with infliximab (remicade) when etanercept (enbrel) has failed or vice versa: Data from the sture registry showing that switching tumour necrosis factor alpha blockers can make sense. Ann Rheum Dis 62(12):1195-1198

22. Miyasaka N, Takeuchi T, Eguchi K (2006) Guidelines for the proper use of etanercept in Japan. Mod Rheumatol 16(2):63-67

23. Mpofu S, Fatima F, Moots RJ (2005) Anti-tnf-alpha therapies: They are all the same (aren't they?). Rheumatology (Oxford) 44(3):271-273

24. Anderson PJ (2005) Tumor necrosis factor inhibitors: clinical implications of their different immunogenicity profiles. Semin Arthritis Rheum 34(5 Suppl 1):19-22

25. Weaver AL (2004) Efficacy and safety of the anti-tnf biologic agents. Mod Rheumatol 14(2):101-112

26. Tracey D, Klareskog L, Sasso EH, Salfeld JG, Tak PP (2008) Tumor necrosis factor antagonist mechanisms of action: a comprehensive review. Pharmacol Ther 117(2):244-279
27. Cohen G, Courvoisier N, Cohen JD, Zaltni S, Sany J, Combe B (2005) The efficiency of switching from infliximab to etanercept and vice versa in patients with rheumatoid arthritis. Clin Exp Rheumatol 23(6):795-800

28. Laas K, Peltomaa R, Kautiainen H, Leirisalo-Repo M (2008) Clinical impact of switching from infliximab to etanercept in patients with rheumatoid arthritis. Clin Rheumatol 27(7):927-932

29. Sandborn WJ (2003) Strategies for targeting tumour necrosis factor in ibd. Best Pract Res Clin Gastroenterol 17(1):105-117

30. Maini RN, Breedveld FC, Kalden JR, Smolen JS, Davis D, Macfarlane JD, Antoni C, Leeb B, Elliott MJ, Woody JN, Schaible TF, Feldmann M (1998) Therapeutic efficacy of multiple intravenous infusions of anti-tumor necrosis factor alpha monoclonal antibody combined with low-dose weekly methotrexate in rheumatoid arthritis. Arthritis Rheum 41(9):1552-1563

31. Ideguchi H, Ohno S, Ishigatsubo Y (2007) Risk factors associated with the cumulative survival of low-dose methotrexate in 273 Japanese patients with rheumatoid arthritis. J Clin Rheumatol 13(2):73-78 